\title{
Glacier-bed characteristics of midtre Lovénbreen, Svalbard, from high-resolution seismic and radar surveying
}

\author{
E.C. KING, ${ }^{1}$ A.M. SMITH, ${ }^{1}{ }^{\text {T. MURRAY, }}{ }^{2}$ G.W. STUART ${ }^{3}$ \\ ${ }^{1}$ British Antarctic Survey, Natural Environment Research Council, Madingley Road, Cambridge CB3 OET, UK \\ E-mail: ecki@bas.ac.uk \\ ${ }^{2}$ Department of Geography, School of the Environment and Society, Swansea University, Singleton Park, Swansea SA2 8PP, UK \\ ${ }^{3}$ School of Earth and Environment, University of Leeds, Leeds LS2 9JT, UK
}

\begin{abstract}
We conducted a seismic and radar survey of the central part of midtre Lovénbreen, a small, polythermal valley glacier in Svalbard. We determined the physical properties of the material beneath the glacier by measuring the reflection coefficient of the bed by comparing the energy of the primary and multiple reflections, and deriving the acoustic impedance. By making reasonable assumptions about the properties of the basal ice, we determined the acoustic impedance of the bed material as $(6.78 \pm 1.53) \times 10^{6} \mathrm{~kg} \mathrm{~m}^{-2} \mathrm{~s}^{-1}$. We interpret the material beneath the glacier to be permafrost with up to $\mathbf{5 0} \%$ ice, and we speculate that the material may be frozen talus similar to a deposit observed directly by others beneath another Svalbard glacier. The implication for midtre Lovénbreen is that the basal material beneath the present glacier is not able to support fast flow. We conclude that midtre Lovénbreen has most likely had limited capability for faster flow in the past, with motion dominated by internal deformation. Midtre Lovénbreen is used as a 'study glacier' for the scientific community in Svalbard, and a large number of studies have been based there. Our results show that it cannot be used as an analogue for larger glaciers in Svalbard, having distinct basal boundary conditions.
\end{abstract}

\section{INTRODUCTION}

Svalbard glaciers make a significant contribution to contemporary global sea-level rise $\left(0.056 \mathrm{~mm} \mathrm{a}^{-1}\right.$; Dowdeswell and others, 1997; Van der Wal and Wild, 2001). Quantification of current mass-balance trends of these glaciers is therefore important for predictions of future sea level. This is being accomplished by extrapolation of the results of detailed studies of a small number of glaciers with long mass-balance records, one of which is midtre Lovénbreen (Hagen and Liestøl, 1990; Lefauconnier and Hagen, 1990; Dowdeswell, 1995; Fleming and others, 1997; Hagen and others, 2003). Mass balance is controlled by surface conditions (accumulation and ablation), basal conditions (melting or freezing) and ice dynamics (mass movement from colder to warmer regions).

A number of studies have addressed the surface boundary conditions of midtre Lovénbreen (e.g. surface energy balance (Arnold and others, 2006) and superimposed ice formation (Wadham and others, 2006)), but information about basal boundary conditions and hence likely ice dynamics is more limited. The topography of the bed is known from radar surveys that also determined the distribution of cold and temperate ice (Björnsson and others, 1996; Rippin and others, 2003). The hydraulic properties of the bed were determined in one region of the glacier by Kulessa and Murray (2003) who drilled five boreholes and found little or no hydraulic conductivity in four of them. Prior to this study, the only spatially extensive information about the bed of the glacier came from studies of the forefield (Glasser and Hambrey, 2001), but this may not be representative of the majority of the current bed because forefield sediments overlie Carboniferous and Permian sedimentary rocks while the glacier overlies Proterozoic metamorphic rocks (Hjelle, 1993).

Ground-penetrating radar is sensitive to dielectric properties and was used here principally to determine the internal structure of the glacier, in particular the distribution of temperate ice. Seismic surveying measures the acoustic properties of the subsurface, and seismic energy is better able to penetrate below the bed of a glacier, while remaining relatively insensitive to the internal structure. The two methodologies therefore complement each other. The key aim of this paper is to determine the nature of the bed of midtre Lovénbreen using seismic investigation and draw implications for the past and future dynamics of the glacier.

\section{LOCATION AND PREVIOUS WORK}

Midtre Lovénbreen $\left(78^{\circ} 53^{\prime} \mathrm{N}, 12^{\circ} 03^{\prime} \mathrm{E}\right)$ is a polythermal glacier in northwest Spitsbergen, in the Svalbard archipelago (Fig. 1). The glacier is approximately $5 \mathrm{~km}$ long and $1 \mathrm{~km}$ wide, has a maximum thickness of approximately $180 \mathrm{~m}$ and terminates on land. It has an elevation range of 50$460 \mathrm{~m}$ a.s.l. and the equilibrium-line elevation is $400 \mathrm{~m}$ (Björnsson and others, 1996). Data collected by the Norwegian Polar Institute on midtre Lovénbreen constitute one of the longest records of mass balance in the Arctic, covering nearly 40 years since 1967/68 (Hagen and Liestøl, 1990; Lefauconnier and others, 1999). Over this period, the glacier had a mean negative mass balance of $-0.37 \mathrm{~m} \mathrm{a}^{-1}$ w.e. The mean rate of elevation change has been increasing since the 1930s (Kohler and others, 2007) from $0.15 \mathrm{~m} \mathrm{a}^{-1}$ for the period 1936-62 to $0.69 \mathrm{ma}^{-1}$ between 2003 and 2005 . Retreat over the last 100 years has been about $1 \mathrm{~km}$, and volume losses over the same time have probably been approximately $25 \%$, based on former marginal positions and trimlines (Hansen, 1999). The volume loss between 1967 and 1988 was measured by Hagen and Liestøl (1990) as 10\% of the 1967 volume.

Ice thickness and bed topography have been mapped by radar (Björnsson and others, 1996; Rippin and others, 2003). The maximum ice thickness is about $180 \mathrm{~m}$. Velocities on 


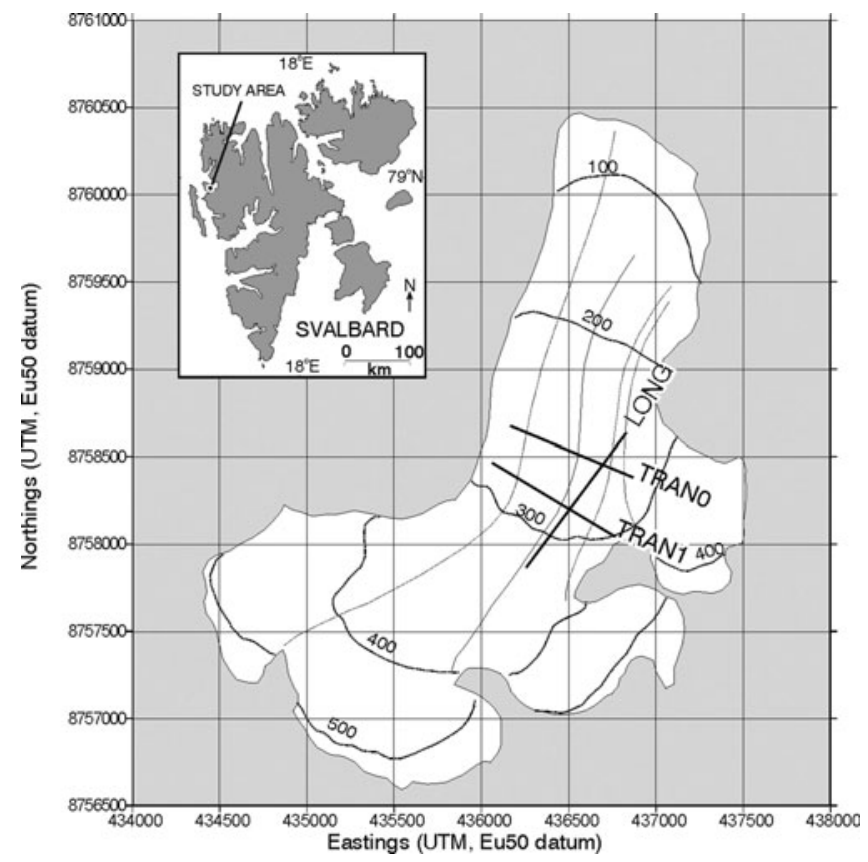

Fig. 1. Location of seismic lines on midtre Lovénbreen. Surface elevation in metres above sea level. Longitudinal lines are flow unit boundaries from Hambrey and others (2005). Inset shows study area in Svalbard archipelago.

the centre line of midtre Lovénbreen range from $4.4 \mathrm{~m} \mathrm{a}^{-1}$ (Björnsson and others, 1996) to $7.3 \mathrm{~m} \mathrm{a}^{-1}$ (Liestøl, 1988) and the flow is not sufficient to replenish the ablation zone, so the surface profile is steepening (Hagen and Liestøl, 1990). Borehole measurements have shown that the base of the central part of the glacier is at the pressure-melting point (Björnsson and others, 1996) and that the hydraulic conductivity of the bed is low (Kulessa and Murray, 2003). A basal layer of temperate ice is situated in the central upper part of the glacier, with a maximum thickness of approximately $50 \mathrm{~m}$ (Björnsson and others, 1996). The polythermal boundary is marked on high-frequency radar by the onset of extensive scattering.

\section{DATA ACQUISITION AND PROCESSING}

Three lines were surveyed on the middle section of the glacier using both seismic and radar techniques, two transverse to glacier flow and one longitudinal (Fig. 1). The lines were located to cross the boundary between temperate ice and cold ice at the glacier bed, and were positioned using hand-held global positioning system (GPS) receivers

Table 1. Line locations

\begin{tabular}{lccccc}
\hline & Latitude & Longitude & $\begin{array}{c}\text { Eastings } \\
\text { (ED50) }\end{array}$ & $\begin{array}{c}\text { Northings } \\
\text { (ED50) }\end{array}$ & $\begin{array}{c}\text { UTM } \\
\text { zone }\end{array}$ \\
\hline LONG_start & 78.87537 & 12.03657 & 436268 & 8757892 & $33 X$ \\
LONG_end & 78.88322 & 12.06185 & 436856 & 8758739 & $33 X$ \\
TRAN0_start & 78.88244 & 12.02899 & 436145 & 8758688 & $33 X$ \\
TRAN0_end & 78.87996 & 12.06368 & 436877 & 8758374 & $33 X$ \\
TRAN1_start & 78.88032 & 12.02615 & 436072 & 8758455 & $33 X$ \\
TRAN1_end 78.87694 & 12.05884 & 436756 & 8758042 & $33 X$ \\
& & & & &
\end{tabular}

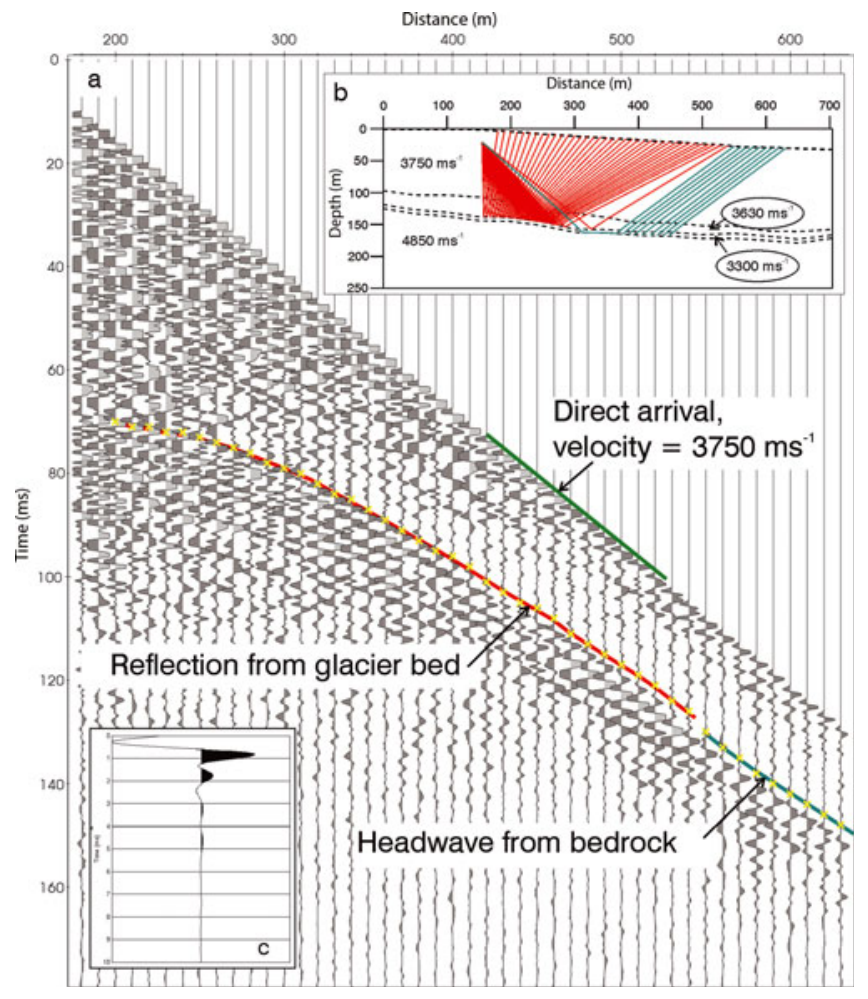

Fig. 2. Wide-angle reflection/refraction record from line LONG. (a) Seismic data composited from two shots fired at $155 \mathrm{~m}$ on line LONG to produce a 48-channel record with $10 \mathrm{~m}$ spacing between the geophones. The first arrival is the direct wave through the ice, which has a constant velocity of $3750 \mathrm{~m} \mathrm{~s}^{-1}$. The second arrival is the reflection from the bed of the glacier, which fades out at the $540 \mathrm{~m}$ distance point. On the outer channels, the second arrival is the refraction from the bedrock surface. The lines show the arrival times of rays traced through the model depicted in the inset (b). (c) Average wavelet derived from the unprocessed shot records.

and an electronic distance meter (EDM). Surface elevation profiles were measured with theodolite and EDM. The line locations are summarized in Table 1. While acquiring the seismic reflection data we also fired some larger charges with greater shot-to-geophone separations (wide-angle/ refraction shooting) to determine seismic wave speeds in the subsurface.

\section{Seismic data}

\section{Acquisition and processing: reflection data}

The seismic reflection data were collected using $80 \mathrm{~g}$ (line TRAN1) or $120 \mathrm{~g}$ (lines TRAN0 and LONG) high-explosive charges fired in $20 \mathrm{~m}$ deep holes drilled using a hot-water drill. The receiver spread comprised $24100 \mathrm{~Hz}$ geophones, distributed 12 either side of a centrally placed shot. The data were sampled at a $0.1 \mathrm{~ms}$ interval after an analogue bandpass filter $(4-1000 \mathrm{~Hz})$ was applied, using a Bison 9024 seismograph. Record length was $400 \mathrm{~ms}$, sufficient to record both the primary reflection from the glacier bed and its first multiple. The shot and geophone intervals were 20 and $10 \mathrm{~m}$, respectively, resulting in six-fold coverage and a maximum source-receiver offset of $115 \mathrm{~m}$. The data processing is summarized in Table 2. The seismic signals have a very wide bandwidth of approximately $100-900 \mathrm{~Hz}$, because the shots were fired in ice, and the snow cover, which usually attenuates high frequencies, was thin. The source wavelet is of short duration, as would be expected from an 


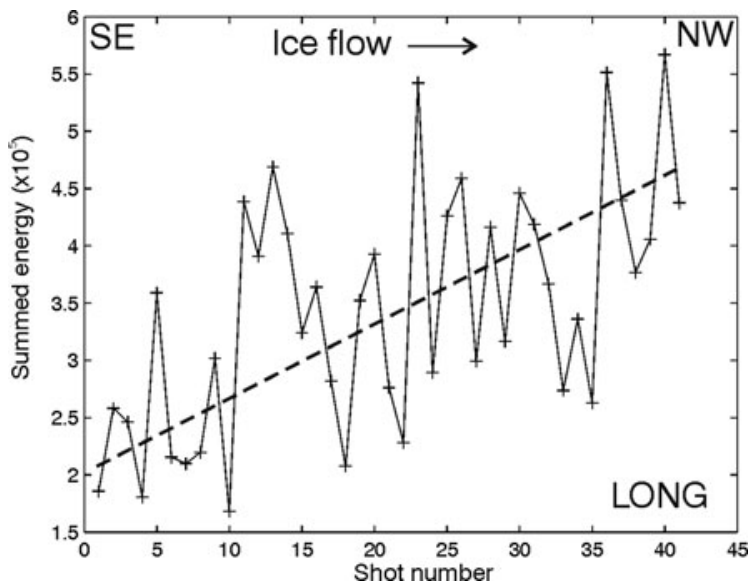

Fig. 3. Shot energy for line LONG. Summed energy from all channels for first $40 \mathrm{~ms}$ of each shot. Differences from shot to shot may be due to local variations in the properties of the ice around the charge. Increasing trend down-glacier may correlate with cumulative ablation, exposing formerly deeper ice.

impulsive source (Fig. 2c). The peak frequency of the source wavelet is about $700 \mathrm{~Hz}$. The final processed sections have a peak frequency of about $350 \mathrm{~Hz}$ following bandpass filtering and stacking.

The charges were fired at $20 \mathrm{~m}$ depth in order to minimize the amplitude of surface-coupled shear waves (ground roll), which for shallower shots cause interference with the reflection from the bed of the glacier. The only significant disadvantage of firing the shot at $20 \mathrm{~m}$ is the presence of a shot ghost following the primary reflection, that is energy that travelled upwards from the shot, reflected off the surface and then followed a similar ray path to the energy direct from the shot. For display purposes only, the shot-ghost energy was largely removed from the reflection records using a predictive deconvolution operator.

To investigate any changes in the material properties of the glacier bed, it is necessary to measure relative changes in the amplitude of the bed reflection. In surveys with multifold acquisition, each trace of the final processed record is the sum of traces from different shots and different geophones. This process averages out any random variation in the amount of seismic energy generated by each shot. This means that relative amplitude variations in the bed reflection are not obscured by changes in the input energy. However, in our case, the fold is low (six-fold) so the effect of averaging is weak and two or three shots that were stronger or weaker than normal could produce spurious amplitude variation in the final processed section. Analysis of the amount of energy transmitted direct from shot to geophones showed considerable variation (Fig. 3). Hence we included a processing step that assessed shot-to-shot energy variation then applied a scalar multiplier to balance the shots prior to normal move-out correction and stacking (for details of the method, see the Appendix).

\section{Acquisition and processing: wide-angle reflection/ refraction data}

We recorded data on line LONG in a wide-angle reflection/ refraction configuration. Shots were fired at $20 \mathrm{~m}$ depth at points 155 and $665 \mathrm{~m}$ along the line into reversed 48-channel arrays. Charge size was $300 \mathrm{~g}$ and the maximum source-receiver offset was $475 \mathrm{~m}$. Figure 2a shows
Table 2. Seismic processing sequence

\section{Data input}

Edit bad traces

Assign geometry

Elevation correction

Balance shots based on first arrival energy

Apply dip move-out correction

Six-fold stack

Migration

For display:

Bandpass filter (pass band $80-700 \mathrm{~Hz}$ )

Deconvolution for shot ghost removal

the record for the shot at $155 \mathrm{~m}$. The first arrivals are the direct waves through the ice, travelling at $3750 \pm 50 \mathrm{~m} \mathrm{~s}^{-1}$. The next arrival, which was recorded at the closest geophone at $69 \mathrm{~ms}$, is interpreted as the reflection from the bed. This event fades out at an offset between shot and geophone of $385 \mathrm{~m}$ (540 m distance) and is not seen on the last nine traces, so there is no wide-angle reflection or refraction from the bed of the glacier at larger shot-receiver offsets. On the last nine traces, there is an almost linear event that arrives between 128 and $148 \mathrm{~ms}$. We make two observations concerning this event. Firstly, the event is delayed 3-4 ms compared with a linear extrapolation of the bed reflection. Secondly, the event has the same polarity as the bed reflection and direct wave. The strongest hypotheses for the origin of this event are that it is the headwave from the top of bedrock or that it is the wide-angle reflection of the surface ghost. The surface ghost has opposite polarity to the bed reflection, so this is ruled out as an explanation. We discuss the results of a test of the hypothesis that the event is the headwave from the bedrock interface in the next section.

\section{Radar data}

The radar data were acquired with a pulseEKKO 100 groundpenetrating radar system, using an antenna separation of $2.0 \mathrm{~m}$, a stop-go mode of acquisition with a station spacing of $0.5 \mathrm{~m}$, and antennae with a centre frequency of $100 \mathrm{MHz}$. Two common-midpoint surveys were conducted for velocity control. A basic processing sequence was used that involved bandpass filtering $(60-120 \mathrm{MHz}$ pass band), spherical divergence correction, elevation correction and migration. The elevation correction and migration were both done using a wave speed in ice of $0.168 \mathrm{~m} \mathrm{~ns}^{-1}$. A more detailed analysis of these data was presented by Hambrey and others (2005). Here we use the data only to provide a measure of the depth to the bed and to the temperate ice surface.

\section{RESULTS}

The seismic and radar data for the three lines are shown in Figures 4-6. On the seismic lines there are few coherent reflections from within the glacier. The bed is a prominent positive polarity event, indicative of an interface with an increase in acoustic impedance (the product of seismic wave speed and density). The glacier is $90-160 \mathrm{~m}$ thick in the region of our survey. A second reflection follows the bed reflection at a variable delay time of 3-8 ms on most of the records, suggesting a basal layer of some kind. 


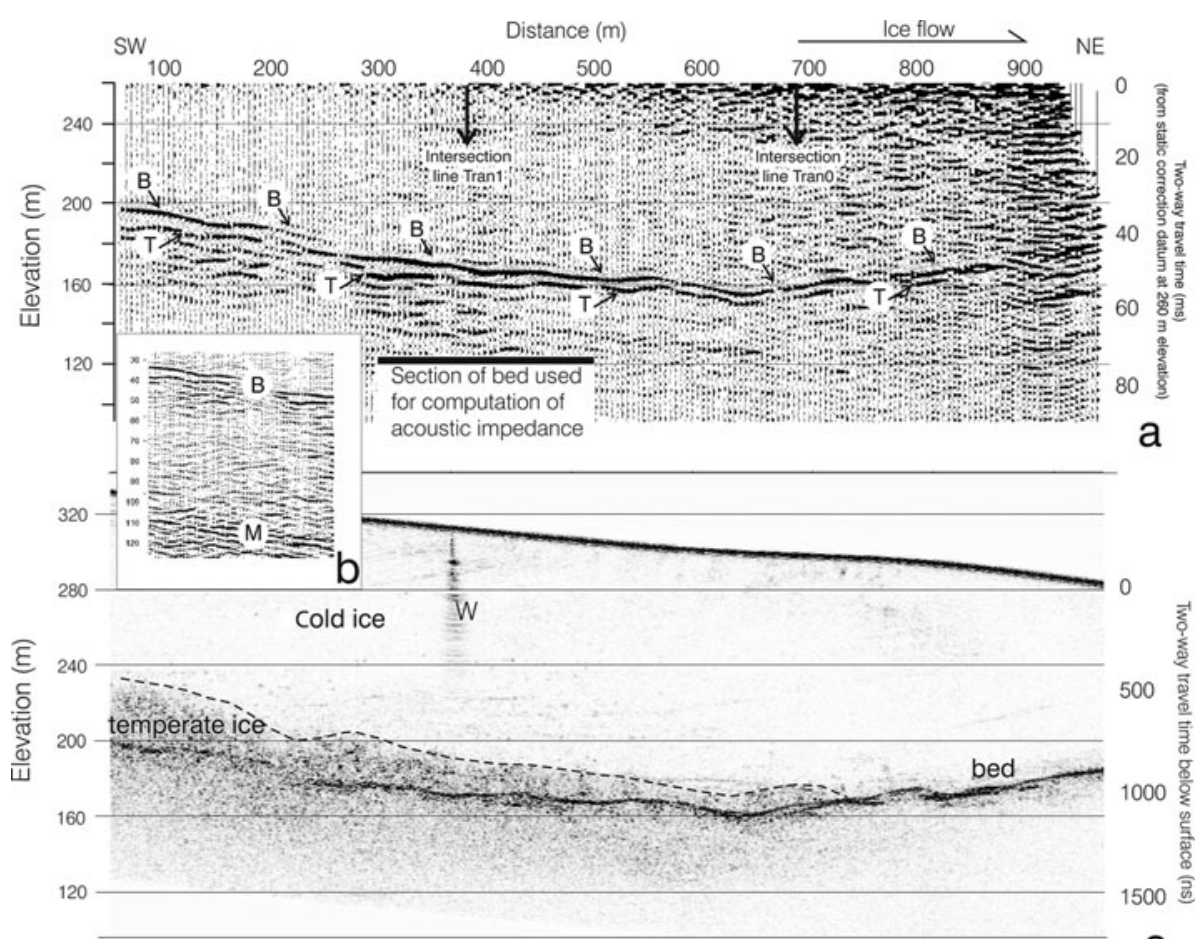

C

Fig. 4. Seismic and radar data for line LONG. (a) Seismic data. Ice flow is from left to right. An elevation correction to a datum at $260 \mathrm{~m}$ a.s.I. has been applied. The first reflection (B) is the glacier bed. The second reflection (T), 3-5 ms later than the bed reflection, is interpreted as the base of a layer of permafrost which may be frozen talus. Elevation scale is based on an average wave speed in ice of $3750 \mathrm{~m} \mathrm{~s}^{-1}$. (b) Inset shows the first $360 \mathrm{~m}$ of the line with an extended time axis. The multiple of the bed reflection is marked M. Vertical axis is time in milliseconds below the static correction datum. In this representation, the arrival time of the multiple is not double the arrival time of the bed reflection. (c) Radar data. Dipping reflectors intersecting the surface suggest that ice from progressively deeper within the glacier is exposed at the surface, with increasing distance downstream. Diffraction from a detonator wire in one of the seismic shot holes is marked W. Higheramplitude reflections near the bed $70-750 \mathrm{~m}$ along the profile are from the zone of temperate ice. Elevation scale is based on a wave speed in ice of $0.168 \mathrm{~m} \mathrm{~ns}^{-1}$.

The main feature of the radar profiles is the region of higher-amplitude scattering near the bed of the glacier. This scattering region, reported first on this glacier by Björnsson and others (1996), is interpreted as the temperate ice zone.

\section{Seismic velocities and depth conversion}

We have two objectives here. Firstly we wish to determine the acoustic wave speed in the bedrock beneath the glacier, and secondly we wish to compare estimates of the thickness of the glacier based on seismic and radar data in order to answer the question 'Are acoustic and electromagnetic waves reflecting off the same interface at the glacier bed?'.

The radar data show the distribution of temperate and cold ice beneath the survey lines. The acoustic wave speed in the cold ice was measured from the direct arrival on the shot records (Fig. 2) at $3750 \pm 50 \mathrm{~m} \mathrm{~s}^{-1}$. The wave speed in the temperate ice is assumed to be $3630 \pm 30 \mathrm{~ms}^{-1}$ (Atre and Bentley, 1993). To construct an initial velocity model, we used these wave speeds, the surveyed surface profile, the depth to the cold-ice/warm-ice boundary, and the depth to the bed (both derived from the radar data using a radar wave speed of $0.168 \mathrm{~m} \mathrm{~ns}^{-1}$; Hambrey and others, 2005). We also included a $1.1 \mathrm{~m}$ thick snow layer, based on short-offset refraction data, together with snow pits measured at the time (Arnold and others, 2006) and our own observations from shot-hole drilling. We calculated an average velocity of $888 \pm 26 \mathrm{~m} \mathrm{~s}^{-1}$ for the snow layer, based on a reversed refraction profile at one location on line LONG. We traced ray paths through the model from shot to receivers using the rayinvr software (Zelt and Smith, 1992) (Fig. 2b). This modelling was conducted for both up-glacier and downglacier shooting directions and gave good agreement between model and observation for the bed reflection and a good match to the apparent velocity for energy refracted along the bedrock surface. However, the initial results produced arrival times lower than the observed times for the bedrock headwaves. We therefore introduced an additional layer beneath the glacier, with a lower velocity than the ice (such that no headwaves would be produced from its upper surface), and produced a better arrival time match. The introduction of this extra layer beneath the glacier bed is compatible with the observation of an event on the reflection profile (Fig. 4a) which arrives after the bed reflection. The model bedrock velocity that gave the best match to the apparent velocity on both up-glacier and down-glacier shots was $4850 \pm 110 \mathrm{~m} \mathrm{~s}^{-1}$.

We next compare ice-thickness estimates for seismic and radar techniques for each of the three survey lines. The velocity model developed for ray-tracing analysis of line LONG was effective for determining a bedrock refraction velocity but represented the temperature structure of the glacier only as a bimodal cold-ice/temperate-ice case. A step-change in temperature and acoustic wave speed is unrealistic and was improved upon in the following way.

We first developed a temperature model by assuming that the temperate-ice/cold-ice boundary (as determined from the radar profiles) is the $0^{\circ} \mathrm{C}$ isotherm, and that outside the area of temperate ice the bed is at $0^{\circ} \mathrm{C}$ (i.e. at the pressure-melting 


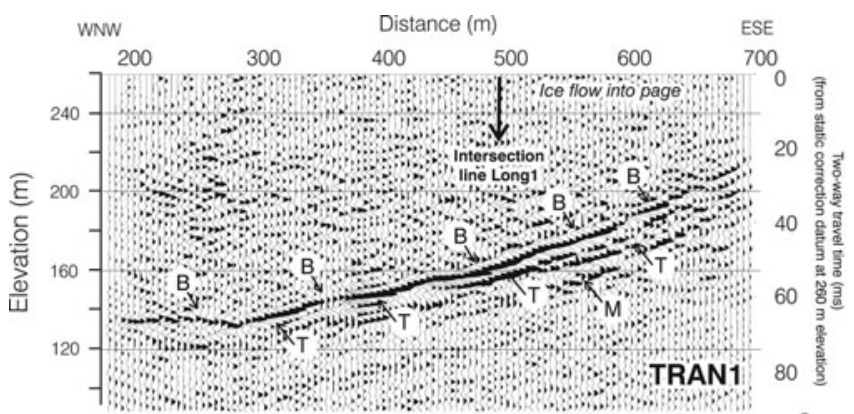

a$$
0
$$

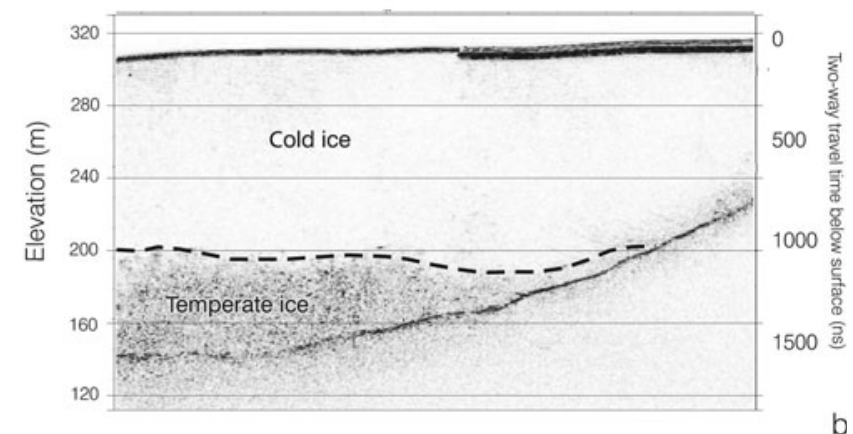

Fig. 5. Seismic and radar data for line TRAN1. (a) Seismic data. Ice flow is into the page. Reflector B is the bed, $T$ is the base of the frozen talus layer and $M$ is a peg-leg multiple within that layer. (b) Radar data. The warm ice zone is about $50 \mathrm{~m}$ thick in the deepest part of the line.

point as this is a relatively thin glacier). Robin (1958) showed that a rapid decrease in seismic velocity with increasing temperature begins $0.3-0.5^{\circ} \mathrm{C}$ below the pressure-melting point, hence we expect that the change in seismic wave speed between cold ice and temperate ice will begin at the $-0.5^{\circ} \mathrm{C}$ isotherm. We assumed that the temperature gradient in the lower part of the glacier is $2^{\circ} \mathrm{C}(100 \mathrm{~m})^{-1}$, based on borehole temperature measurements (Björnsson and others, 1996). Thus the $-0.5^{\circ} \mathrm{C}$ isotherm was modelled at $25 \mathrm{~m}$ above the top of the temperate ice or the bed (Fig. 7).

We observed a wave velocity of $3750 \pm 50 \mathrm{~ms}^{-1}$ from the long-offset records shot on line LONG and we take this as the cold-ice velocity, using it for all ice colder than $-0.5^{\circ} \mathrm{C}$. We take the temperate ice velocity to be $3630 \pm 30 \mathrm{~ms}^{-1}$ (Atre and Bentley, 1993) and use this for all ice at $0^{\circ} \mathrm{C}$. We apply a linear transition between these two temperature zones.

Hence, for each line we produced a velocity model (the TRAN0 model is shown as Fig. 7) and calculated bed depth below surface using the seismic reflection data. Our calculation of ice thickness from the seismic data has an estimated accuracy of $\pm 2.5 \mathrm{~m}$, based on uncertainty in the velocity measurements and in the onset times for the bed reflection.

We compared the seismic ice-thickness measurements to those derived from the radar reflection travel times, using a uniform velocity for the radar wave speed of $0.168 \mathrm{~m} \mathrm{~ns}^{-1}$ (Hambrey and others, 2005). The estimated accuracy of the radar-derived ice thickness is $\pm 1 \mathrm{~m}$. Figure $8 \mathrm{a}-\mathrm{c}$ show that there is no significant difference between the seismic and radar-derived ice thicknesses on all three lines. We conclude that the two techniques are imaging the same interface.

Uncorrected variation in the snow depth from our average value may account for the small differences in ice thickness calculated from seismic and radar data (Fig. 8). The electromagnetic wave speed in snow is faster than in

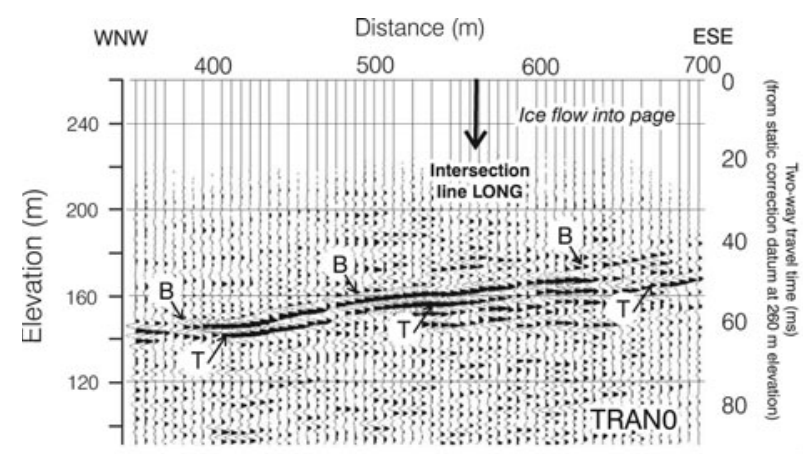

a

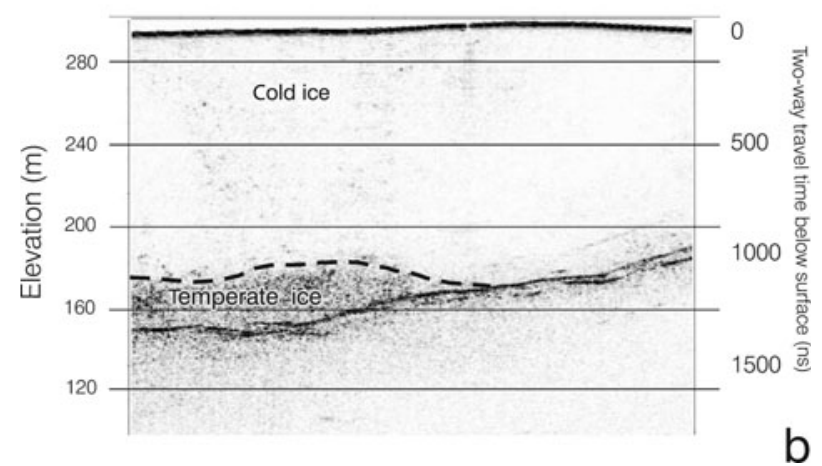

Fig. 6. Seismic and radar data for line TRANO. (a) Seismic data. Annotation as for Figure 4. (b) Radar data. The warm ice layer is about $30 \mathrm{~m}$ thick.

ice, while the acoustic wave speed in snow is slower than in ice. Therefore any small variation in snow thickness is exaggerated when computing the thickness of the glacier using the two methods.

\section{Properties of the bed material from seismic analysis}

Acoustic impedance at the bed

The strength of a seismic reflection from an interface such as the glacier bed is dependent on the contrast in physical properties on either side of the interface. To determine the

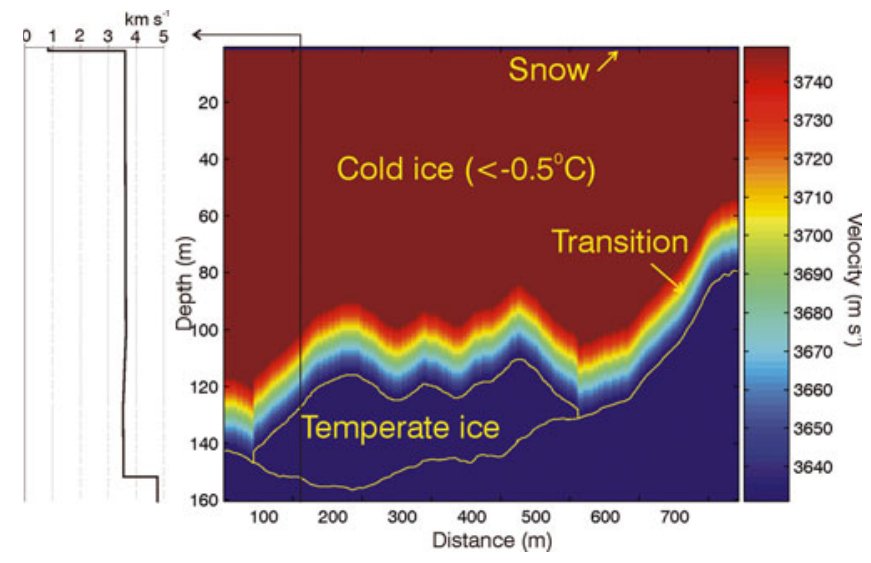

Fig. 7. Example of the velocity model used to convert seismic travel times to depths. Measured seismic wave velocities were $888 \pm 26 \mathrm{~m} \mathrm{~s}^{-1}$ in snow and $3750 \pm 50 \mathrm{~m} \mathrm{~s}^{-1}$ in cold ice. We used a temperate-ice wave velocity of $3630 \pm 30 \mathrm{~m} \mathrm{~s}^{-1}$ in temperate ice. The transition between cold and temperate ice is assumed to be linear over a $25 \mathrm{~m}$ zone, a value determined by the temperature gradient measured by Björnsson and others (1996). 


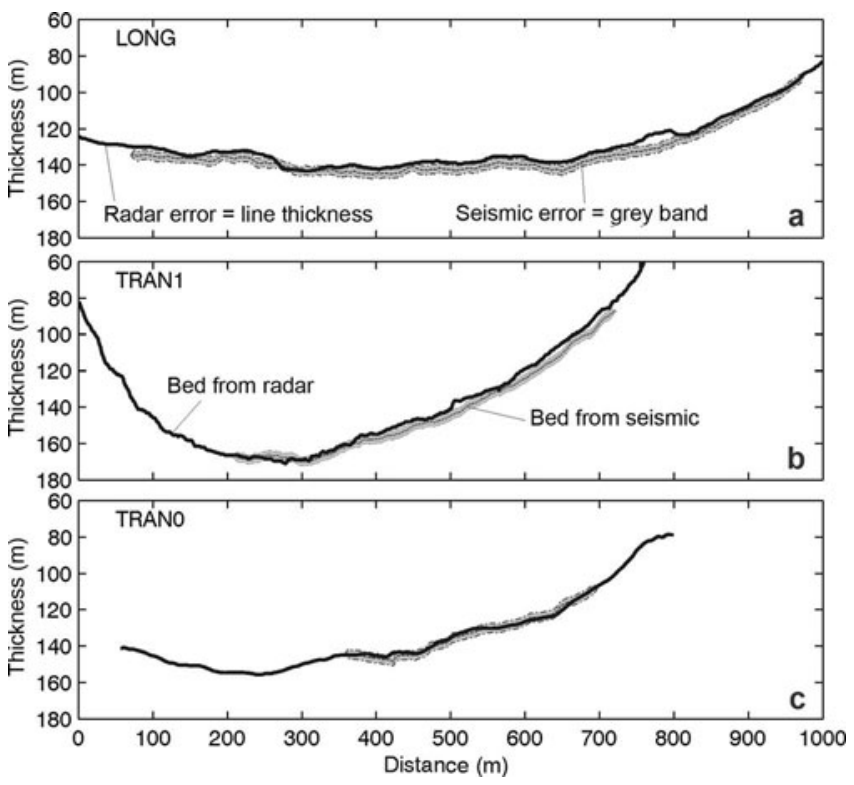

Fig. 8. Comparison of glacier thickness derived from seismic and radar data. The radar-determined values are the solid black lines. The seismic-derived values are the grey shading, representing $\pm 2.5 \mathrm{~m}$ around the best determination.

physical properties of the basal materials, we proceeded as follows. The reflection coefficient of the bed was determined by comparing the ratio of the energy in the bed reflection to that in its first multiple, using the relationship (which assumes that surface reflection is without loss of energy) (modified after Roethlisberger, 1972):

$$
\frac{E_{1}}{E_{2}}=\frac{4}{R^{2}} \mathrm{e}^{4 a h} .
$$

$E_{1}$ and $E_{2}$ are the wavelet energies (the sum of the squared amplitude values; in our case over the first period of the wavelet) of the bed and multiple reflections, respectively. $R$ is the amplitude reflection coefficient, $h$ is the ice thickness and $a$ is the amplitude attenuation coefficient (note that Roethlisberger (1972, p.9) used an attenuation coefficient defined in terms of energy, rather than amplitude). The reflection coefficient $(R)$ is proportional to the acoustic impedance contrast at the reflecting interface:

$$
R=\frac{Z_{\mathrm{b}}-Z_{\mathrm{i}}}{Z_{\mathrm{b}}+Z_{\mathrm{i}}}
$$

$Z_{\mathrm{b}}$ is the acoustic impedance (the product of compressional wave velocity and density) of the bed material and $Z_{i}$ is that of the basal ice. We have observations of $E_{1} / E_{2}$ and $h ; Z_{i}$ lies within a range that we will estimate, allowing us to determine $Z_{\mathrm{b}}$.

The basal ice at midtre Lovénbreen has not been sampled, so we consider two cases that cover the range of possible circumstances. In the first case we assumed clear ice near the bed and in the second we assumed a basal ice layer of a few metres with debris inclusions providing $10 \%$ of the volume. Because the seismic and radar techniques give the same values for the ice thickness (within the errors), any sediment-laden basal ice layer can be no more than about $2.5 \mathrm{~m}$ thick. In each case we assumed reasonable values for the density and wave speed in order to derive its acoustic impedance, $Z_{i}$. The minimum value for $Z_{i}$ is found when the ice is sediment-free. In this circumstance the value is $(3.32 \pm 0.03) \times 10^{6} \mathrm{~kg} \mathrm{~m}^{-2} \mathrm{~s}^{-1}$, based on a wave speed in temperate ice of $3630 \pm 30 \mathrm{~ms}^{-1}$ and ice density of $915 \pm 5 \mathrm{~kg} \mathrm{~m}^{3}$ (e.g. Smith and others, 2002). For sedimentladen ice we assumed temperate ice with $10 \%$ rock fragments. We estimated the bulk properties based on simple proportions, using the Wyllie velocity equation (Wyllie and others, 1956):

$$
\begin{gathered}
\frac{1}{V}=\frac{\phi_{\text {ice }}}{V_{\text {ice }}}+\frac{\phi_{\text {rock }}}{V_{\text {rock }}} \\
\rho=\phi_{\text {ice }} \cdot \rho_{\text {ice }}+\phi_{\text {rock }} \cdot \rho_{\text {rock }},
\end{gathered}
$$

where $V$ is wave speed, $\phi$ is the proportion of ice or rock, and $\rho$ is the density of the components.

We used wave speeds of $3630 \pm 30 \mathrm{~m} \mathrm{~s}^{-1}$ and densities of $915 \pm 5 \mathrm{~kg} \mathrm{~m}^{-3}$ for ice. The rocks exposed in the headwalls of midtre Lovénbreen are Proterozoic gneiss, mica-schist and phyllite (Hjelle, 1993; Hambrey and others, 1999), with a density range between 2400 and $2900 \mathrm{~kg} \mathrm{~m}^{-3}$ (e.g. Telford and others, 1976), so we adopt a value of $2700 \pm 200 \mathrm{~kg} \mathrm{~m}^{-3}$. We take the wave speed in rock to be $4850 \pm 110 \mathrm{~m} \mathrm{~s}^{-1}$ (from the seismic refraction results and Birch, 1942). These assumptions give values for density for the debris-laden ice of $1094 \pm 63 \mathrm{~kg} \mathrm{~m}^{-3}$ and for its wave speed of $3724 \pm$ $44 \mathrm{~m} \mathrm{~s}^{-1}$. We used an amplitude attenuation value of $0.8 \times 10^{-3} \mathrm{~m}^{-1}$, suitable for ice where the mean annual temperature is about $-10^{\circ} \mathrm{C}$ (value converted from the energy attenuation quoted by Jarvis and King (1993) and Smith and others (2002)). The two end-member values for the acoustic impedance of the basal ice $\left(Z_{\mathrm{i}}\right)$ are therefore $(3.32 \pm 0.03) \times$ $10^{6} \mathrm{~kg} \mathrm{~m}^{-2} \mathrm{~s}^{-1}$ for clean ice and $(4.07 \pm 0.31) \times 10^{6} \mathrm{~kg} \mathrm{~m}^{-2} \mathrm{~s}^{-1}$ for debris-laden ice. It is most likely that the basal zone of the glacier is debris-bearing, so we adopt the value of $(4.07 \pm 0.31) \times 10^{6} \mathrm{~kg} \mathrm{~m}^{-2} \mathrm{~s}^{-1}$ for $Z_{\mathrm{i}}$.

To calibrate the reflection coefficient, we measured the wavelet energies of the bed and multiple reflections (marked $B$ and $M$, respectively, in Fig. 4b) on the near-offset traces of shots on line LONG where the bed is parallel to the surface. This occurs between 300 and $500 \mathrm{~m}$ along line LONG (Fig. 4a) (the bed dips downstream over this section because the data are elevation-corrected; however, the surface dips downstream with the same slope). This part of the bed is the only part of the three lines that satisfies the assumptions of Equation (1); elsewhere the general dip or local undulations of the bed prevent the use of the method. We determined $R$ as $0.25 \pm 0.05$ using Equation (1) and derived $Z_{b}$ from Equation (2), using the value of $Z_{i}$ derived above. The calculated value of $Z_{\mathrm{b}}$ was $(6.78 \pm 1.53) \times 10^{6} \mathrm{~kg} \mathrm{~m}^{-2} \mathrm{~s}^{-1}$.

The calculated value for $Z_{b}$ can be influenced by reflectors in close proximity to the bed reflector. The 'thin bed' effect (Widess, 1973) causes an increase in the apparent reflection strength due to the constructive interference between wavelets reflected from the top and bottom of a thin unit. In our case, both a layer of debris-laden ice above the bed and the sub-bed unit have this potential. For a basal ice layer with the properties described above, constructive interference could result in an increase in amplitude of $20-30 \%$ if the layer was $2 \mathrm{~m}$ thick and the upper surface was a sharp, rather than a transitional, boundary. This situation would change the ratio of the primary and multiple energy (Equation (1)) and produce an apparent $R$ value higher than the true one. For a $25 \%$ enhancement by constructive interference, we find that the calculated $Z_{\mathrm{b}}$ would be $(7.73 \pm 1.38) \times 10^{6} \mathrm{~kg} \mathrm{~m}^{-2} \mathrm{~s}^{-1}$, a 


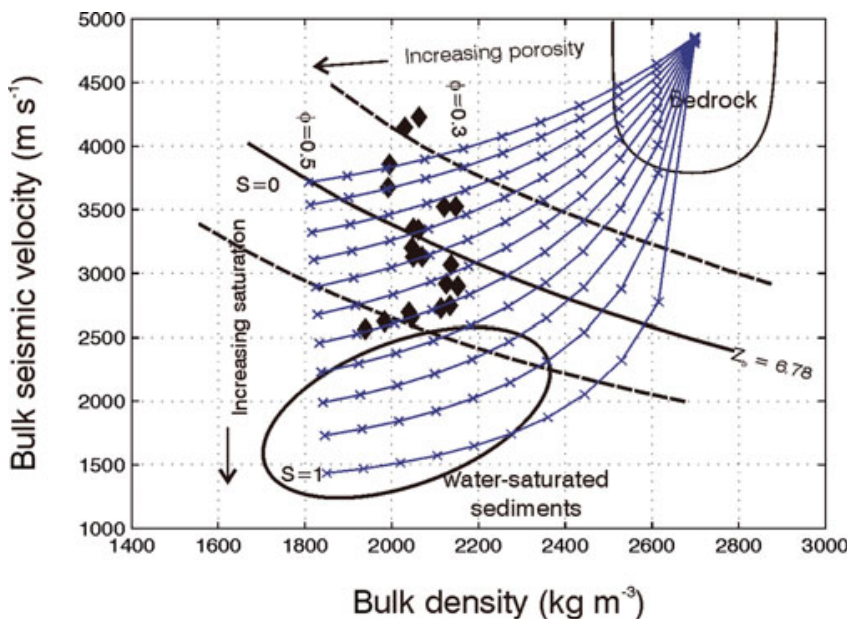

Fig. 9. Curve of constant acoustic impedance for the bed of midtre Lovénbreen plotted in velocity/density space (units: $10^{6} \mathrm{~kg} \mathrm{~m}^{-2} \mathrm{~s}^{-1}$ ). Solid line is the value computed from the seismic data from line LONG which is $6.78 \times 10^{6} \mathrm{~kg} \mathrm{~m}^{-2} \mathrm{~s}^{-1}$; dashed lines show range of uncertainty of $\pm 1.53 \times 10^{6} \mathrm{~kg} \mathrm{~m}^{-2} \mathrm{~s}^{-1}$. Typical velocity/density values for bedrock, permafrost (diamonds) and water-saturated till are shown (Morgan, 1969; Roethlisberger, 1972; Kurfurst, 1976; Barrett and Froggatt, 1978; Zimmerman and King, 1986; Smith, 1997). Blue lines are the values of velocity and density for a three-phase mixture of ice, water and rock using the method of Zimmerman and King (1986). Lines are loci of constant saturation in steps of 0.1. Crosses mark porosity in steps of 0.05 from 0.0 to 0.5 .

difference of $0.95 \times 10^{6} \mathrm{~kg} \mathrm{~m}^{-2} \mathrm{~s}^{-1}$. As this difference is less than the uncertainty, constructive interference due to a thin basal ice layer is not significant. In respect of the sub-ice unit, the wavelet reflected from the base does not interfere with the main lobes of the wavelet reflected from the top at all points where the thickness is greater than $4 \mathrm{~m}$, based on a wavelet period of 1.4-1.5 ms (Fig. 2c) and a wave speed in the sub-ice unit of $3300 \mathrm{~ms}^{-1}$. The time separation between the two reflectors on the section of line LONG where we calculated the basal impedance is everywhere more than $3 \mathrm{~ms}$ on the unprocessed shot records. Therefore the derivation of the basal impedance is not influenced by constructive interference associated with the sub-ice unit.

\section{What is the bed material?}

Thus our best estimate of the acoustic impedance of the bed material is $(6.78 \pm 1.53) \times 10^{6} \mathrm{~kg} \mathrm{~m}^{-2} \mathrm{~s}^{-1}$. We now consider what that bed material might be. Figure 9 compares this impedance value with the impedance ranges for likely subglacial materials. The values for the bedrock field are those given above, based on a composition of gneiss, micaschist and phyllite. The water-saturated sediment field is based on values published by Morgan (1969), Roethlisberger (1972), Kurfurst (1976), Barrett and Froggatt (1978) and Smith (1997). The permafrost data were compiled by Smith and others (2002) from sources cited in that paper. The range of impedance values (including the uncertainty) falls below that of bedrock, mostly above that for water-saturated sediments and bisects the field for permafrost. We conclude that the bed material is either permafrost of some kind or shares the acoustic characteristics of permafrost.

A number of theoretical and experimental studies have been undertaken to determine the range of seismic velocities in permafrost, and these were summarized by Carcione and

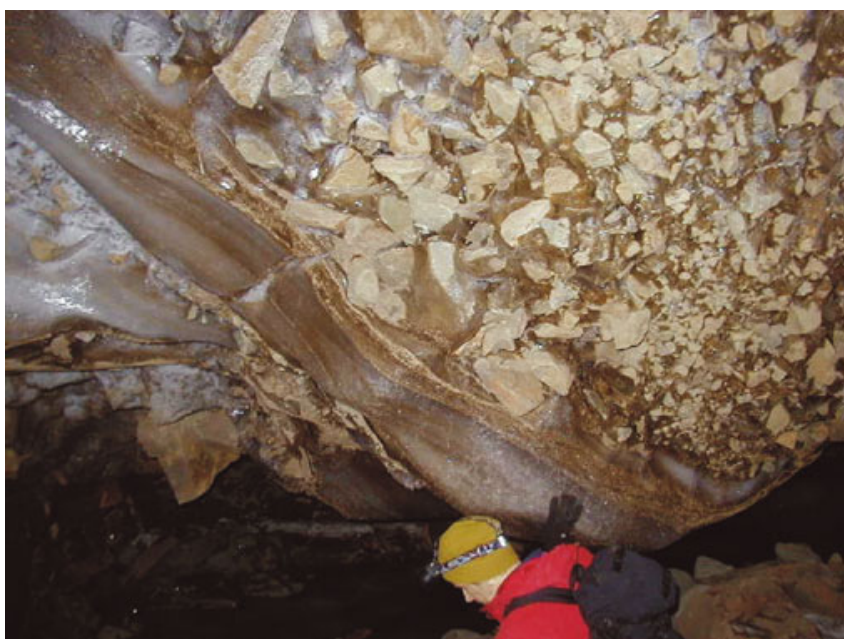

Fig. 10. Photograph taken in a subglacial tunnel beneath Larsbreen, Svalbard, showing an avalanche-derived talus deposit overridden by the glacier. The frozen talus comprises layers of clear ice and layers of clast-supported angular rock debris (photograph courtesy of O. Humlum, first published in Humlum, 2005).

Seriani (1998). We used the model for unconsolidated permafrost of Zimmerman and King (1986) to compute the velocity and density of mixtures comprising bedrock, ice and water with a range of values for porosity and water saturation (Fig. 9). A wide range of values for porosity and water saturation can provide a solution matching the range of bed impedance. While at one extreme the measured bed impedance can be matched by a mix of $92.5 \%$ bedrock and $7.5 \%$ water, the majority of the possible mixtures involve some ice. We have no independent geophysical evidence that would allow determination of where in the spectrum between 50\% rock: $50 \%$ ice and $92.5 \%$ rock: $7.5 \%$ water the bed of midtre Lovénbreen lies.

One possibility is that the material beneath midtre Lovénbreen is similar to the material observed in a natural tunnel beneath Larsbreen, Longyeardalen, about $115 \mathrm{~km}$ southeast of midtre Lovénbreen (Humlum, 2005; Humlum and others, 2007) (Fig. 10). The main body of Larsbreen has overridden an avalanche-derived rock glacier, creating a layer between the main glacier ice and the underlying bedrock that comprises interlayered ice lenses and layers of clast-supported angular rock debris in an ice matrix. Overall, the visually estimated volumetric ice content of the rock glacier was $60-80 \%$ and the photographs indicate that different bands have ice content between $100 \%$ and $30 \%$. The interface between the bedrock and the rock glacier was sharp and the bedrock surface showed no indication of abrasion caused by basal sliding of the rock glacier (Humlum and others, 2007).

Another possibility is that the material beneath the glacier is a frozen diamict. The geophysical data cannot distinguish grain-size differences at this scale. In seeking to distinguish between these cases, we have to consider what is more likely geologically and geomorphologically.

The geometry of the unit and the geological setting suggest that it is reasonable to interpret the bed material as frozen talus. On lines TRAN1 and TRANO (Figs 5 and 6) the unit thickens towards the southeast margin of the valley, which is consistent with it being a talus apron. The headwalls of midtre Lovénbreen comprise gneiss, mica-schist and phyllite, 

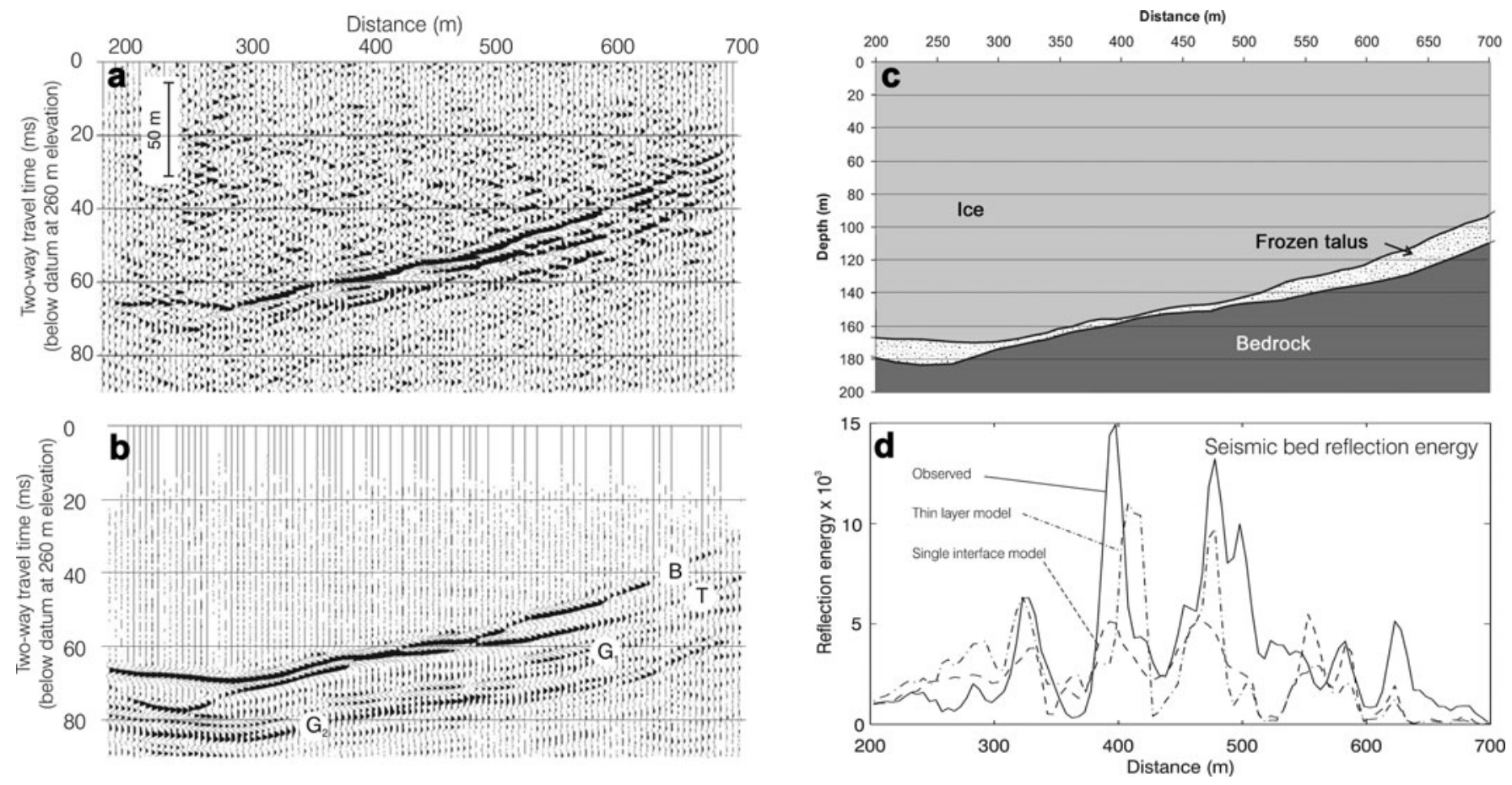

Fig. 11. Wave equation modelling of line TRAN1. (a) Observed seismic data. (b) Synthetic seismic section generated using model shown in (c). Events are: $\mathrm{B}$ - bed reflection; $\mathrm{T}$ - base of frozen talus; $\mathrm{G}_{1}$ - shot ghost from bed, i.e. energy reflected by the surface before reflecting from the bed, which should arrive about $11 \mathrm{~ms}$ later than the primary reflection; $\mathrm{G}_{2}$ - shot ghost from the bedrock surface. The synthetic data were generated as shot records and then put through the same processing sequence as the observed data. The shot ghost from the bedrock is more prominent on the model data probably because whereas the model has a well-defined talus-bedrock interface, the real situation is that the interface is more diffuse and undulating on a small scale, resulting in a smaller amplitude reflection for both primary and ghost. (d) Seismic bed reflection energy. Observed data (solid line) show high values over lows in the bed and low values over highs. Single interface model (dashed line) shows the same pattern but a lower magnitude. Reflection energy is best modelled using a thin layer of frozen talus over bedrock.

metamorphic rocks that are generally resistant to erosion (Hjelle, 1993; Hambrey and others, 1999). The glacier is small in size, has a low flowspeed and is mostly coldbedded; therefore, present-day basal erosion rates are likely to be low. The combination of rock type and valley topography makes it unlikely that the upper part of the glacier has generated large quantities of fine-grained till. It appears more likely that the glacier overrode talus material with poorly sorted angular clasts.

One independent line of evidence comes from a hydraulic conductivity experiment conducted close to line TRAN1. The conclusion of this work was that the bed material is mostly frozen and supports only a small hydraulic conductivity (Kulessa and Murray, 2003). During hot-water drilling of access holes, Kulessa and Murray (2003) found that the ice-bed interface was poorly defined, and surmised that this was due to regelation of basal ice into the underlying substrate. Four out of five boreholes drilled to the bed had little or no hydraulic conductivity. The fifth site did demonstrate water evacuation but with a low conductivity value of $(1.9 \pm 0.5) \times 10^{-5} \mathrm{~m} \mathrm{~s}^{-1}$.

The results of the hydraulic conductivity experiments are consistent with the theory that the bed is comprised of frozen talus. The bedrock clasts (medium- to high-grade metamorphic rock) are likely to have little or no permeability; therefore, any hydraulic conductivity must take place around the clasts, not through them. If the interstitial water is mostly frozen, then the majority of boreholes to the bed will have no hydraulic conductivity but there may be some limited water pathways at the ice-clast interfaces.
We speculate that the valley now occupied by midtre Lovénbreen had extensive rockfall-fed talus aprons prior to the formation of the glacier. If the glacier then advanced over this material in the same way as Larsbreen, a layer of frozen talus could have been preserved. In the absence of direct sampling of the sub-bed material, we cannot prove the talus hypothesis, thus we continue with a description of the bed material as permafrost (talus?). We next consider what the thickness of the permafrost (talus?) unit is.

\section{Determination of subglacial permafrost thickness}

There was a reflection on the seismic data on each of the seismic lines that arrived 3-8 ms after the reflection from the glacier bed (Figs 4-6). We interpret this reflection as the interface between the permafrost layer and the bedrock. If we assume a seismic wave speed through the permafrost layer of $3300-3500 \mathrm{~m} \mathrm{~s}^{-1}$ (which is compatible with the wide-angle reflection/refraction interpretation), then the thickness of the layer is $5-13 \mathrm{~m}$. From Figure 9, a wave speed in the permafrost of $3300-3500 \mathrm{~m} \mathrm{~s}^{-1}$ implies a material comprised of $40-45 \%$ rock, 5-15\% water and $45-50 \%$ ice. There are places where it was not possible to distinguish separate reflections, (e.g. 400-420 m on line TRAN1). When reflecting interfaces come close together, the reflected seismic wavelets begin to interfere, creating constructive and destructive interference which produces variation in the reflection amplitude. We next consider seismic wavefield modelling to determine to what extent this thin-layer phenomenon affects our data. 

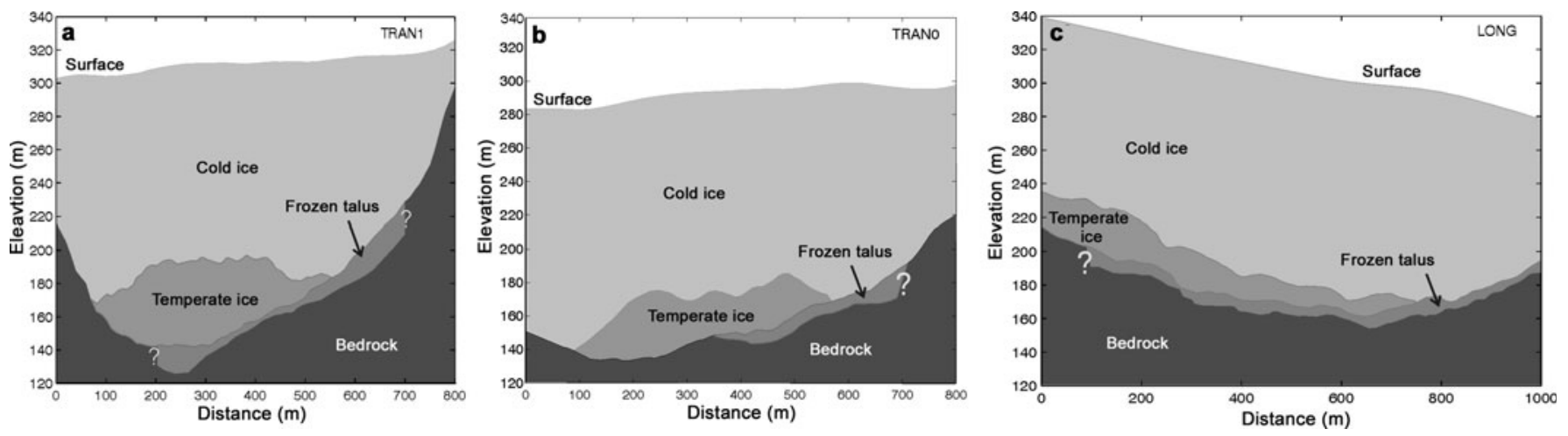

Fig. 12. Interpreted glacial and subglacial structure beneath the seismic lines on midtre Lovénbreen. We conclude that over most of the area surveyed, the glacier sits on a bed of permafrost which we speculate is frozen talus. The talus is up to $13 \mathrm{~m}$ thick, with the thickest sections towards the southeast flank of the glacial valley. Question marks denote the limits of the seismic data.

To confirm that our interpretation matched all aspects of the data, we constructed two acoustic models of line TRAN1 and computed the seismic response of each. One model included a variable-thickness layer of permafrost, the other assumed that the same material was $>100$ m thick everywhere. We used a finite-difference wave equation modelling technique available in the ProMax ${ }^{\circledR}$ seismic-processing software. This involves defining a model space using a series of polygons with appropriate velocity and density parameters. The positions of shots and geophones are also defined, as is the peak frequency and wavelet type. We used $350 \mathrm{~Hz}$ and a Ricker wavelet (even though this wavelet is broader than the source wavelet derived from the unprocessed shot records) in order to better match the processed section which was bandpass-filtered and stacked. Starting from the shot location, the propagation of a seismic wave through successive gridcells was then computed, based on the physical properties of the cell. Reflection and transmission at each model boundary were treated correctly. The result is a set of model shot records, equivalent in geometry to the observed shot records, which we then put through the same processing sequence as the observed data, to provide as close a comparison as possible.

The variable-thickness (0.5-13.0 m thick) model is shown as Figure 11. This model shows that, for a $350 \mathrm{~Hz}$ wavelet, where the subglacier layer is more than $\sim 6 \mathrm{~m}$ thick, the modelled reflections from the top and the base of the layer are distinct. Where the layer is between $\sim 3$ and $\sim 6 \mathrm{~m}$ thick, the top and basal reflections constructively interfere with each other. Below $3 \mathrm{~m}$ thickness, the separate reflections cannot be distinguished.

Interference between the reflections from two closely spaced interfaces can either increase or decrease the amplitude of the seismic return. Undulations in the reflecting horizon also change the amplitude by focusing or defocusing the wave fronts. The results from the two models allow us to estimate the relative importance of the two effects. The amplitude of the bed reflection is best represented by an energy term which is computed by summing the squared amplitude values over a complete cycle of the reflected wavelet. The reflection energy results for the two models are shown in Figure 11d. It is clear that the bed topography alone can account for the pattern of highs and lows in the reflection energy (the highs scatter energy outside the recording array, thus reducing the amplitude, while the lows focus energy onto the recording array with the opposite effect), although the magnitude is not well modelled. By introducing a variable thickness layer lying between ice and bedrock, the magnitude of the reflection energy variation is modelled much more closely. The match between observed and modelled reflection energies could be improved even further by more detailed variations in the thickness of the permafrost layer. However, this would only solve for a two-dimensional case, whereas it is clear from line LONG that there is also significant bed undulation in the along-flow direction and therefore some of the variability in observed bed reflection energy on TRAN1 could be due to unknown cross-line bed topography.

A reasonable match between modelled and observed reflection strengths on line TRAN1 was therefore achieved using the measured bed topography and a frozen talus layer of varying thickness, with constant physical properties. This result, combined with the observation that the reflection immediately following the bed arrival (Figs 4a, 5a and 6a) is remarkably continuous over all three lines, suggests that the properties of the subglacier layer do not vary significantly laterally.

The interpreted permafrost (talus?) thicknesses are shown in Figure 12. On line TRAN0 the layer is $\sim 5 \mathrm{~m}$ thick over most of the profile, and thickens to $\sim 10 \mathrm{~m}$ over the last $60 \mathrm{~m}$ at the eastern end of the profile. On line TRAN1, which is further up-glacier, the interpreted thickness is variable between 0.5 and $13.0 \mathrm{~m}$. On line LONG, the interpreted thickness is mostly between 5.0 and $7.5 \mathrm{~m}$. There is no obvious correlation between permafrost thickness and the presence or absence of overlying temperate ice. The implication from the acoustic impedance value for the permafrost is that there is likely to be some water present, hence the ice matrix is temperate and there is little or no thermal discontinuity between the base of the glacier and the permafrost.

\section{CONCLUSIONS}

Our interpretation of the seismic and radar data from midtre Lovénbreen is that the bed of the glacier comprises a thin layer of permafrost over bedrock. Based on the geology and geometry of the setting, we favour an interpretation that the permafrost is a frozen talus deposit. This is a somewhat speculative interpretation but the one which seems to best fit all the observations. The layer varies between 0.5 and $13.0 \mathrm{~m}$ in thickness, with the greatest thickness adjacent to the 
southeast side of the glacier. The composition of the frozen talus is thought to be $40-45 \%$ rock, 5-15\% water and $45-$ $50 \%$ ice. We suggest that similar basal conditions may exist beneath some other small valley glaciers in Svalbard where the glacier shape, orientation and geological setting are similar. In the absence of a glacier in the valley currently occupied by midtre Lovénbreen, the dominant landform type can be expected to be talus aprons flanking the sides of the valley. The example of Larsbreen shows that a glacier can develop over the talus in such a situation, leaving significant quantities undisturbed because erosive action was absent at the bed. We emphasize that this is not a model applicable to all small valley glaciers on Svalbard as we suspect that the influence of geology is particularly important.

These characteristics are significantly different from the generally larger surge-type glaciers in Svalbard (Jiskoot and others, 2000). An example of this type of glacier is Bakaninbreen, which has a thick layer of debris-rich basal ice and where some parts of the bed have reflection properties characteristic of unfrozen sediment (Murray and others, 2000; Smith and others, 2002). The geological settings of Bakaninbreen and midtre Lovénbreen are very different. Bakaninbreen has bedrock of sandstone and limestone, which are relatively soft rocks compared with the gneiss, mica-schist and phyllite that form the bedrock of the upper parts of midtre Lovénbreen. In addition, Bakaninbreen is more than three times as long as midtre Lovénbreen and parts occupy a formerly marine trough. Thus Bakaninbreen has softer source rocks and a longer erosion path compared with midtre Lovénbreen, conditions conducive to the generation of large amounts of fine-grained till. The evidence from drilling and sampling the basal sediments beneath Bakaninbreen suggests the presence of copious fine sediment (Murray and Porter, 2001).

The implication for midtre Lovénbreen is that the basal material beneath the present footprint of the glacier is not able to support fast flow. It is neither bare bedrock against which a pressurized water film could be generated to provide lubrication, nor is it soft till capable of dilation and failure under shear. In the past, when the glacier was larger, the distal part lay over softer rocks and the till of the present forefield. Therefore, the bed of the glacier would have had mixed properties and we suggest that motion would have been dominated by internal deformation rather than basal processes. We therefore concur with Jiskoot and others (2000) that midtre Lovénbreen is not a surge-type glacier.

Midtre Lovénbreen is used as a 'study glacier' for the scientific community in Svalbard, and a large number of studies have been based there. Our results cast doubt on its use as an analogue for larger glaciers in Svalbard, having distinct basal boundary conditions. Furthermore, hot-water drilling techniques are unlikely to make hydraulic connection with the ill-defined bed of the glacier.

\section{ACKNOWLEDGEMENTS}

Financial support for this study was provided by the UK Natural Environment Research Council (NERC) under the ARCICE thematic programme (grant GST/02/2192). The success of the fieldwork was due in major part to the excellent support provided by B. Newham and N. Cox at the NERC Arctic station, and N. Alesund on the glacier. We thank O. Humlum for helpful comments and permission to reproduce Figure 10.

\section{REFERENCES}

Arnold, N.S., W.G. Rees, A.J. Hodson and J. Kohler. 2006. Topographic controls on the surface energy balance of a high Arctic valley glacier. J. Geophys. Res., 111(F2), F02011. (10.1029/2005JF000426.)

Atre, S.R. and C.R. Bentley. 1993. Laterally varying basal conditions beneath Ice Streams B and C, West Antarctica. J. Glaciol., 39(133), 507-514.

Barrett, P.J. and P.C. Froggatt. 1978. Densities, porosities and seismic velocities of some rocks from Victoria Land, Antarctica. New Zeal. J. Geol. Geophys., 21(2), 175-187.

Birch, F., ed. 1942. Handbook of physical constants. Washington, DC, Geological Society of America.

Bjørnsson, H. and 6 others. 1996. The thermal regime of sub-polar glaciers mapped by multi-frequency radio-echo sounding. J. Glaciol., 42(140), 23-32.

Carcione, J.M. and G. Seriani. 1998. Seismic and ultrasonic velocities in permafrost. Geophys. Prospect., 46(4), 441-454.

Dowdeswell, J.A. 1995. Glaciers in the High Arctic and recent environmental change. Philos. Trans. R. Soc. London, Ser. A, 352(1699), 321-334.

Dowdeswell, J.A. and 10 others. 1997. The mass balance of circum-Arctic glaciers and recent climate change. Quat. Res., $48(1), 1-14$.

Fleming, K.M., J.A. Dowdeswell and J. Oerlemans. 1997. Modelling the mass balance of northwest Spitsbergen glaciers and responses to climate change. Ann. Glaciol., 24, 203-210.

Glasser, N.F. and M.J. Hambrey. 2001. Styles of sedimentation beneath Svalbard valley glaciers under changing dynamic and thermal regimes. J. Geol. Soc. London, 158(4), 697-707.

Hagen, J.O. and O. Liestøl. 1990. Long-term glacier massbalance investigations in Svalbard, 1950-88. Ann. Glaciol., 14, 102-106.

Hagen, J.O., K. Melvold, F. Pinglot and J.A. Dowdeswell. 2003. On the net mass balance of the glaciers and ice caps in Svalbard, Norwegian Arctic. Arct. Antarct. Alp. Res., 35(2), 264-270.

Hambrey, M.J., M.R. Bennett, J.A. Dowdeswell, N.F. Glasser and D. Huddart. 1999. Debris entrainment and transfer in polythermal valley glaciers. J. Glaciol., 45(149), 69-86.

Hambrey, M.J. and 7 others. 2005. Structure and changing dynamics of a polythermal valley glacier on a centennial timescale: Midre Lovénbreen, Svalbard. J. Geophys. Res., 110(F1), F01006. (10.1029/2004JF000128.)

Hansen, S. 1999. A photogrammetrical, climate-statistical and geomorphological approach to the post Little Ice Age changes of the Midre Lovénbreen glacier, Svalbard. (Master's thesis, University of Copenhagen.)

Hjelle, A. 1993. Geology of Svalbard. Oslo, Norsk Polarinstitutt. (Polarhåndbok 7.)

Humlum, O. 2005. Holocene permafrost aggradation in Svalbard. In Harris, C. and J.B. Murton, eds. Cryospheric systems: glaciers and permafrost. London, Geological Society, 119-130. (Special Publication 242.)

Humlum, O., H.H. Christiansen and H. Juliussen. 2007. Avalanchederived rock glaciers in Svalbard. Permafrost Periglac. Process, 18(1), 75-88.

Jarvis, E.P. and E.C. King. 1993. The seismic wavefield recorded on an Antarctic ice shelf. J. Seism. Explor., 2(1), 69-86.

Jiskoot, H., T. Murray and P. Boyle. 2000. Controls on the distribution of surge-type glaciers in Svalbard. J. Glaciol., 46(154), 412-422.

Kohler, J. and 7 others. 2007. Acceleration in thinning rate on western Svalbard glaciers. Geophys. Res. Lett., 34(18), L18502. (10.1029/2007GL030681.)

Kulessa, B. and T. Murray. 2003. Slug-test derived differences in bed hydraulic properties between a surge-type and non-surge-type Svalbard glacier. Ann. Glaciol., 36, 103-109.

Kurfurst, P.J. 1976. Ultrasonic wave measurements on frozen soils at permafrost temperatures. Can. J. Earth Sci., 13(11), 1571-1576. 
Lefauconnier, B. and J.O. Hagen. 1990. Glaciers and climate in Svalbard: statistical analysis and reconstruction of the Brøggerbreen mass balance for the last 77 years. Ann. Glaciol., 14, 148-152.

Lefauconnier, B., J.O. Hagen, J.B. Örbæk, K. Melvold and E. Isaksson. 1999. Glacier balance trends in the Kongsfjorden area, western Spitsbergen, Svalbard, in relation to the climate. Polar Res., 18(2), 307-313.

Liestøl, O. 1988. The glaciers in the Kongsfjorden area, Spitsbergen. Nor. Geogr. Tidsskr., 42(4), 231-238.

Morgan, N.A. 1969. Physical properties of marine sediments as related to seismic velocities. Geophysics, 34(4), 529-545.

Murray, T. and P.R. Porter. 2001. Basal conditions beneath a softbedded polythermal surge-type glacier: Bakaninbreen, Svalbard. Quat. Int., 86(1), 103-116.

Murray, T. and 6 others. 2000. Glacier surge propagation by thermal evolution at the bed. J. Geophys. Res., 105(B6), 13,49113,507 .

Rippin, D. and 6 others. 2003. Changes in geometry and subglacial drainage of Midre Lovénbreen, Svalbard, determined from digital elevation models. Earth Surf. Process. Landf., 28(3), 273-298.

Robin, G. de Q. 1958. Glaciology III. Seismic shooting and related investigations. In Norwegian-British-Swedish Antarctic Expedition, 1949-52, Scientific Results, Vol. V. Oslo, Norsk Polarinstitutt.

Roethlisberger, H. 1972. Seismic exploration in cold regions. I. CRREL Monogr. II-A2a.

Smith, A.M. 1997. Basal conditions on Rutford Ice Stream, West Antarctica from seismic observations. J. Geophys. Res., 102(B1), 543-552.

Smith, A.M., T. Murray, B.M. Davison, A.F. Clough, J. Woodward and $\mathrm{H}$. Jiskoot. 2002. Late surge glacial conditions on Bakaninbreen, Svalbard, and implications for surge termination. J. Geophys. Res., 107(B8), 2152. (10.1029/2001JB000475.)

Telford, W.M., L.P. Geldart, R.E. Sheriff and D.A. Keys. 1976. Applied geophysics. Cambridge, etc., Cambridge University Press.

Van de Wal, R.S.W. and M. Wild. 2001. Modelling the response of glaciers to climate change by applying volume-area scaling in combination with a high resolution GCM. Climate Dyn., 18(3-4), 359-366.

Wadham, J., J. Kohler, A. Hubbard, A.-M. Nuttall and D. Rippin. 2006. Superimposed ice regime of a high Arctic glacier inferred using ground-penetrating radar, flow modeling, and ice cores. J. Geophys. Res., 111(F1), F01007. (10.1029/2004JF000144.)

Widess, M.B. 1973. How thin is a thin bed? Geophysics, 38(6), $1176-1180$

Wyllie, M.R.J., A.R. Gregory and L.W. Gardner. 1956. Elastic wave velocities in heterogeneous and porous media. Geophysics, 21(1), 41-70

Zelt, C.A. and R.B. Smith. 1992. Seismic traveltime inversion for 2-D crustal velocity structure. Geophys. J. Int., 108(1), 16-34.

Zimmerman, R.W. and M.S. King. 1986. The effect of the extent of freezing on seismic velocities in unconsolidated permafrost. Geophysics, 51(6), 1285-1290.

\section{APPENDIX}

\section{BALANCING THE SHOT ENERGY}

The amplitude of the reflection from an interface is determined by the amplitude of the incident acoustic wave, the geometry of the interface, the geometry of any other close-by interfaces and the contrasts in acoustic properties across all interfaces. The absolute amplitude of a seismic reflection is difficult to measure in the field because of the number of uncontrolled variables, particularly the calibration of geophones and the efficiency of the coupling of the geophone to the ground surface. However, relative changes in amplitude contain valuable information about changes in the acoustic properties or geometry of the reflectors. It is therefore important to minimize shot-to-shot variations in the source or receiver characteristics.

For homogeneous ice, use of identical charges, placed at the same depth, recorded by the same instrument, with the same geophones should produce very similar records for the direct waves from each shot. However, analysis of the data from midtre Lovénbreen showed that the different shots were very variable. This variability was assessed by measuring the total energy in the combined direct arrivals, that is the compressional and shear waves and the surface-coupled shear waves that travel direct from the source to the geophones. We term this the 'source energy' and calculate it by summing the energy (i.e. the square of the amplitudes) on all 24 traces over the first $40 \mathrm{~ms}$ of each shot record. To the first order this included similar waveforms for all shots, while excluding the bed reflection. This measure of source energy would ideally be the same for each shot; however, we found that this was not the case (Fig. 3). There is considerable shot-to-shot variability (the maximum energy value on line LONG is $>300 \%$ of the minimum), as well as an overall trend (an increase with downstream distance on line Long 1 ). There are three potential reasons for differences in the source energy: (1) the geophone coupling and response; (2) the ray paths (i.e. the routes the seismic energy takes between source and geophones); and (3) shot effects.

Geophone coupling: The geophones were spaced at $10 \mathrm{~m}$ intervals and the shots at $20 \mathrm{~m}$ intervals. Moving the spread between shots involved unclipping the geophones from the cable, moving the cable along the line by $20 \mathrm{~m}$ and reclipping the 22 undisturbed geophones into the new channels, while planting two new geophones at the advancing end of the cable. Therefore, each adjacent shot was recorded by 22 geophones that were undisturbed between shots. Hence, variation in geophone coupling or response is not a likely explanation for the variability in recorded source energy.

Ray paths: Because the shot points and geophone spread moved only a short distance along the line $(20 \mathrm{~m})$ in comparison to the size of the geophone spread (230 m long), there was a large overlap between the ray paths from adjacent shots. The effects on the recorded amplitudes of any small-scale $(\sim 10-20 \mathrm{~m})$ variations in the acoustic properties of the near-surface should be averaged out by taking the total source energy across the whole spread. This suggests that the effect of different ray paths should cause little variation in the source energy from shot to shot, though it does not preclude the influence of large-scale changes in the acoustic properties of the glacier.

Shot effects: Possible reasons for variability in the coupling of explosive energy into the glacier are:

1. The length of time between loading the hole and firing the shot, which could affect the degree to which the water used to drill the hole had refrozen around the charge. However, no systematic relationship between source energy and time separating loading and firing was found.

2. Variability in the properties of the ice surrounding the charge. Hambrey and others (2005) describe debris 
layers, clear ice layers and bubbly ice layers which are folded together within the upper part of the glacier. The different physical properties of these layers could affect coupling of shot energy, depending on what type of layer exists at the base of the shot hole.

3. Surface variations (e.g. snow thickness or properties).

4. Failure to initiate some parts of the explosive (each charge comprised several smaller charges secured together by tape and half-hitches in the detonator wires).

We therefore conclude that effects at or immediately around the shot are the most likely reason for source energy variability, although we cannot determine which of these last three possible factors actually cause the variations in source energy. However, as the reflection from the glacier bed is of particular interest, we normalized the source energy for all the shots along each line in the following way. We computed a scalar multiplier for each shot based on its source energy compared with the average source energy in all the shots on the line. This multiplier was then applied to all samples of the shot record. After balancing all the shots in this way, common depth-point gathers were formed, the normal move-out correction was applied and the traces were stacked. Any differences in reflected energy from the bed of the glacier on the final stacked section should arise only from variations in the glacier bed, rather than from any source effects.

MS received 30 March 2007 and accepted in revised form 20 October 2007 